IV Congreso Internacional Estética y Política Poéticas del desacuerdo para una democracia plural 16 y 17 de octubre. Valencia

Doi: http://dx.doi.org/10.4995/CEP4.2019.10489

\title{
Wunderblock. De la representación sin poder: una cinematografía del documento dislocado
}

\author{
Alfonso Legaz \\ Artista multidisciplinar, Máster en Fotografía, Arte y Técnica por la Universidad Politécnica de Valencia, a.legaz@hotmail.com
}

\begin{abstract}
Wunderblock is a documentary video cinematography created by Alfonso Legaz, belonging to the project 20 mirrors happen that the artists Alfonso Legaz and Andrea Garay develop in common between 2015 and 2019. This cinematography, together with the rest of the project materials, investigates from the concept of "exposition" - developed by the philosopher Jean-Luc Nancy (1986) — the problematic of the "exposition" of the individual -and of all singularity-before others, mediating their experience of community and their evidence of existence regimes of dominant representation that reduce and homogenize them.
\end{abstract}

This text analyses aspects of the regime of documentary cinematographic presentation that articulate the figure of the artist producing his work in his work space. From a critical position, the text analyses the effective suppression of the artist's "exposition", from which the dominant form of representation is appropriated that makes fictions pass for truths and, in front of which, Wunderblock opposes a dislocated form of documentary presentation, where critical art and thought, such as Rancière posed, produce a separate aesthetic that, assuming its own limits, establishes its space of action in the consensual body of the real, where meanings are distributed by suspending the sense.

Keywords: Wunderblock, community, Jean-Luc Nancy, critical art, documentary cinematography, dissent, dislocate.

\footnotetext{
Resumen

Wunderblock es una cinematografía videográfica documental creada por Alfonso Legaz, perteneciente al proyecto 20 espejos suceden, que desarrollan en común los artistas Alfonso Legaz y Andrea Garay entre 2015 y 2019. Esta cinematografía, junto al resto de materiales proyectuales, investiga a partir del concepto de "exposición” — desarrollado por el filósofo Jean-Luc Nancy (1986)_ la problemática de la "exposición” del individuo —y de toda singularidad-ante los otros, al mediar su experiencia de comunidad y su evidencia de existencia regímenes de representación dominantes que las reducen y homogeneizan.
}

Este texto analiza aspectos del régimen de presentación cinematográfica documental que articulan la figura del artista produciendo su obra en su espacio de trabajo. Desde una posición crítica, analiza la supresión efectiva de la "exposición" del artista, de la cual se apropia la forma de representación dominante que hace pasar ficciones por verdades y, frente a la cual, Wunderblock opone una forma de presentación documental dislocada, donde arte crítico y pensamiento, tal como Rancière plantease, producen una estética separada que, asumiendo los límites propios, establece su espacio de acción en el cuerpo consensual de lo real, donde se distribuyen los significados suspendiendo el sentido.

Palabras clave: Wunderblock, comunidad, Jean-Luc Nancy, arte crítico, cinematografía documental, disenso, dislocar. 


\section{Introducción}

Wunderblock es una cinematografía videográfica documental creada por Alfonso Legaz, planteada como memoria y parte del proyecto en común 20 espejos suceden (Legaz y Garay, 2019), iniciado en 2015, de mecánica procesual y medio multidisciplinar instalado en el campo de la desocultación, que investiga en torno al acto de comunicación, la experiencia de comunidad y la exposición del individuo ante los otros. El proyecto produce de manera performativa sus objetos e instancias a partir del concepto de "exposición" (de una singularidad ante otra: individuo, pueblo, colectividades, etc), desarrollado por Jean-Luc Nancy en La comunidad desobrada (Nancy, 2001) ${ }^{1}$; concepto imprescindible para vincular lo particular con la ontología del ser-con, modo propio de ser de la existencia en la estética de Nancy. La actividad proyectual opera con fotografía, pintura, videografía no-ficción o testimonio oral, y adopta esta "exposición" (de representación imposible) como sentido de la fuerza motriz y no como matriz de trabajo; implementa elementos del pensamiento occidental —cuerpo, representación o mímesis-que, deconstruidos por Nancy en sus "figuras de lo común" (Massó, 2015), sirven a la hipótesis central del proyecto: el poder sancionador de técnicas de representación documental — visuales y escriturales - aporta la "exposición" como documento de una singularidad corporal expuesta, ocultando la sinceridad de los hechos y la realidad e inhibiendo la experiencia de comunidad.

Este texto coloca el foco en una forma representacional de la cinematográfica documental, una de las representaciones problematizadas en 20 espejos suceden que ha devenido representación crítica desde la "exposición": la presentación cinematográfica documental del artista durante la producción de su obra en su espacio de trabajo. El caso real, una artista plástica - Andrea Garay - lleva a cabo un largo proceso pictórico que es documentado con vídeo y sonido. El objeto de crítica - fraude de la forma de representación dominante - media lo real haciendo pasar ficciones por verdades; con esta impostura significa, distribuye y disciplina un vaciado homogeneizante del cuerpo del artista y del hecho específico de su producción (en esta forma de delirio comunicativo acompañan al cuerpo así presentado significados interpuestos a su existencia singular, así como una trazabilidad esquizoide del objeto producido que se abre paso hacia su recepción, mediación y mercado proclamando ingenuamente un discurso que niega su ser). Este dispositivo dominante, nace en el cine de ficción industrial, influyendo la cinematografía documental, los contenidos en medios de comunicación, en el flujo de Internet y en el arte contemporáneo, construyendo ficciones sociales: neutraliza la "exposición" al pretenderla incorporada a su ficción, que presenta como verdad; pero sin "exposición" no hay experiencia de comunidad, desvela Nancy. Esta "apropiación" (Nancy, 2001, p.174) del ser, colabora hoy al asentamiento en la sociedad de una invisibilidad integral por transparencia extrema, situación demandante de tolerancia extrema para producir un consenso integral que integra un behaviorismo aplicado al ser de la existencia (Baudrillard, 2005, p.15). Silenciar la profunda oscuridad que caracteriza la existencia propia y la existencia del otro, suprime el «en» del en-común (acercando la "comunión" fascista por homogeneización estética) no afectando sólo el campo del arte, sino que embrida toda acción social y en ella lo político, la democracia, ayudando a cubrir con el manto del descrédito cada hecho real, como efecto del contacto del acontecimiento con la toxicidad de su forma representativa dominante.

\section{Desarrollo}

En julio de 2015, mientras estudiaba textos de Nancy sobre la experiencia de comunidad, puse en manos del público materiales de un proyecto propio expuesto por en una galería de arte de Valencia. Decidí partir desde una intervención del otro sobre mi trabajo, constituyéndola en apertura a una investigación artística sobre lo que dice Nancy que nos ocurre viviendo en sociedad: la comunicación, la experiencia de comunidad, la puesta en circulación de la existencia. Antes de concluir la exposición, una mujer interesada en los audios expuestos, una psicoanalista, pidió permiso para transcribirlos para sus clases y sus alumnos. Se trata de diecinueve audios donde un hombre ciego, músico, ofrece testimonio vital de su paso por espacios públicos del Centro Histórico de Valencia — un audio por lugar - que le habían servido de escenario durante los últimos cuarenta años y que hoy sobreviven como teatros, salas de conciertos, aparcamientos o tierra de especulación. Le pedí que, a cambio, escribiese una breve síntesis de cada audio. Aceptó. Tomé las síntesis y propuse a

\footnotetext{
${ }^{1}$ El texto manejado corresponde a la edición en español, La comunidad desobrada, editada por Arena Libros en 2001, con traducción de Pablo Perera (en colaboración con Isidro Herrera y Alejandro del Río). Esta edición incorpora dos ensayos de J.L. Nancy posteriores a la primera edición original en francés: «Del ser-en-común» y «La historia finita»; en adelante la paginación citada en este texto corresponderá a esta edición traducida.
} 
Andrea Garay —artista plástica con interés especial por el retrato - producir una serie pictórica con una premisa: partiendo de un pequeño retrato fotográfico realizado por mí al cantante ciego, pintar diecinueve variaciones de esa representación; cada retrato, singularizado por uno de los textos escritos por la psicoanalista, produciría variaciones formales; Andrea no podría contactar con el hombre ciego durante su proceso. Aceptó. Yo realizaría un documental. Wunderblock se constituye en un tiempo documental del trabajo que fue, del encuentro con Jean-Luc Nancy, de la incertidumbre, de las dificultades del documento para ser, y de lo sobrevenido, pues un descubrimiento en las grabaciones iniciales nos constituyó en equipo para afrontar un largo camino europeo-mediterráneo. Aquí trataremos sólo la presentación cinematográfica del proceso de producción de la serie pictórica.

\section{1. “Cómo hablar de la pintura de un pintor?”, J.L. Nancy, 01:08:10}

La pregunta que se autoformula Nancy en Wunderblock, obliga la descripción de un preliminar que muestra el conflicto que provoca hoy, tiempo de flujos, la representación visual dominante puesta en relación con lo que sabemos, aunque esto último no podamos escogerlo (Burgin, 2004): en este caso sabemos la "exposición”, entre otras cosas.

Nancy afirma que el ser de la existencia tiene su sentido en el "en" del en-común, "No se trata de que yo "tenga" el sentido, ni de que tenga sentido, sino de que soy en el sentido, y soy en él por tanto en el modo exclusivo del ser-encomún" (Nancy, 2001, p.173). Por tanto, ser es en la experiencia de comunidad, aunque la comunidad sea cosa del otro. Analizado ese estar "expuesto" al otro —individuo pero no sólo, todo aquello que es como singularidad (Nancy, 2001, p.167) - como medio por el cual se pone en circulación el ser activándose la experiencia de existencia, en un "en" o en un "con" que permite activar el "envite", requiere sustanciarse ese ser en el "en" desde un modo que Nancy llama "abandono"; en realidad ese "abandono" constituye la misma "exposición", “(...) el abandono mismo comunica, comunica la singularidad a sí misma a través de un infinito afuera, y como este afuera infinito. Hace advenir lo propio (persona, grupo, asamblea, sociedad, pueblo, etc) exponiéndolo" (Nancy, 2001, p.170). Es decir, lo que permite comunicar la evidencia de existencia a nosotros mismos, no es la autopercepción, anteponiendo el yo al nosotros como hacen los niños, sino la confirmación desde ese "afuera" del abandono de lo propio en lo que Nancy llama el "límite", es decir, nuestro límite singular, donde opera el conocimiento de los otros sobre nuestra existencia singular, donde nuestra "exposición" es el advenimiento de un espacio-tiempo como "acontecimiento",

(...) a este advenimiento Heidegger lo denominó Ereignis, es decir, "propiación", pero también y en primer lugar "acontecimiento": el acontecimiento no es lo que tiene lugar, sino la llegada de un lugar, de un espacio-tiempo como tal, el trazado de su límite, su exposición (Nancy, 2001, p.170.).

Llegados aquí, es necesario atender a lo que Deleuze escribe sobre el "acontecimiento":

El estallido, el esplendor del acontecimiento es el sentido. El acontecimiento no es lo que sucede (accidente); está en lo que sucede el puro expresado que nos hace señas y nos espera (....) Es lo que debe ser comprendido, lo que debe ser querido, lo que debe ser representado en lo que sucede. (Deleuze, 1989, p.158).

Aquí, lo que gesticula, lo que debe ser "comprendido", "lo querido" a desocultar, está puesto en relación con que el trabajo de un artista produciendo su obra no puede ser representado más que como ficción declarada y no como documentación de lo real. El "accidente" es el ejercicio corporal del artista con su obra, y la obra atendida como resultado de esa gimnasia en cualquiera de sus estadios emergentes. Al "acontencimiento" le atañe aquello que ha llevado al artista a aceptar ser grabado en su taller, exponerse inútilmente en un documento audiovisual, y aún antes y durante, su pensamiento, sus epifanías y al final su irrepresentable "abandono". Pero, entonces, ¿y la cámara? La máquina tiene limitaciones cuando debe vérselas con aquello aún-no-construido, lo aún no-consensuado como ficción representativa, lo aún-no-incorporado como saber a la versión del Principio de realidad que maneja el operador de cámara: todo aquello que hace al «abandono» también es lo que permite caracterizar como arte cierta producción simbólica y no otra, y eso es tema de ningún "afuera" porque se trata de una "exposición", que no podrá ser presentada de manera alguna, tampoco mediante documento cinematográfico. De la "exposición", Nancy afirma que el peligro autocomplaciente de todo escrito o documento cualquiera de comunicación, es creer que por esa acción de comunicar se presenta la "exposición". Debemos asumir la imposiblidad, pero sin el intento que produce "una repetición de una condición humana que ni siquiera accede a la co-humanidad", todo llevaría a un abismo mayor que la imposibilidad misma de presentación (Nancy, 2001, p.170). 
Deleuze presenta el "acontecimiento" no como idea o concepto, sino como fenómeno caracterizado por su complejidad problemática y problematizante, ahistórico y reterritorializante que no puede ser representado dado que cortaría el paso a la mímesis tradicional o platónica, viejo enfrentamiento desde Aristófanes, "invertir el platonismo significa entonces: mostrar los simulacros, afirmar sus derechos entre los iconos o las copias" (Deleuze, 1989, p.263); siempre hay formas por venir. Cuando Deleuze habla de la noción de presente y analiza sus modos en su Lógica del sentido, describe el que sitúa primero: "el presente desmesurado, dislocado, como tiempo de la profundidad y la subversión" (Deleuze, 1989, p.121). Desde esta idea del presente, presente es aquí llegada de un presente singular, temporalidad de sentido en-común que "insiste y resiste" — como en pocos acontecimientos — además, como singularidad finita pero ilimitada que soporta la durabilidad de la producción artística repitiendo un No que atraviesa las generaciones. De esa concepción de un presente encarnado e inadaptado, surge la decisión de enfrentar una presentación crítica del proceso pictórico de Andrea Garay a la representación dominante mediante una presentación "dislocada": dislocando la representación en su "presente" al que se "abandona" el cuerpo de Andrea movilizado para el trabajo; dislocado como instancia de acceso al "acontecimiento": cuerpo movilizado para y por el trabajo en su obra a partir de su conciencia y sus dispositivos, pulsiones, deconstrucciones, represiones, condensaciones y aplazamientos, su necesidad de ser "en", su pensamiento e ideología, es decir, su singular e inexponible vida psíquica, su indeterminada tolerancia a la incertidumbre más el conocimiento que posee, o cree poseer. Sin embargo, nada de lo anterior puede registrarse sin más mediante máquinas, y luego presentarse sin más mediante máquinas: sólo el "accidente" quedará de la presentación de un proceso de creación que no incorpore sus atributos... oscuros. A pesar de la dificultad, Nancy, tras preguntarse por las posibilidades de presentación o (re)presentación, se responde:

La necesidad del ser-en-común no es la de una ley física, y quien quiera exponerlo debe también exponerse ahí (es lo que puede llamarse "pensamiento", "escritura", y su partición). Tal es, por el contrario, la complacencia que amenaza a todo discurso de la comunidad (al mío también, en consecuencia): creer (re)presentar por su propia comunicación, una co-humanidad cuya verdad, sin embargo, no es una esencia dada y (re)presentable. (Nancy, 2001, p.171).

\subsection{Contexto historiográfico}

No se puede hablar de un género de cine documental que presenta al artista produciendo su obra, tan sólo hay obras separadas en el tiempo, rarezas vinculadas a sus marcos históricos, resistencias a una voz de dominación mediadas por sus técnicas, dispositivos y alcances. Rarezas que proveen a su pesar modos acabados de distribuir significado (sin "acontecimiento" no hay sentido) a la actividad artística y no sólo, reducciendo seres, objetos y hechos; esta herida es el eje militante donde se inscribe Wunderblock como instancia resistente en la sociedad de control: redistribución de las relaciones entre las cosas, las imágenes y las palabras por las representaciones dominantes (Rancière, 2010, p. 77). En el cine de ficción declarada, el problema es otro porque declara la ficción: "sería apasionante analizar el régimen de crédito en todas las artes (...) por supuesto en lo que el cine nos muestra y nos relata" (Derrida, 2002, p.98). El documental, en cambio, es una ficción que orbita un «acontecimiento», alcanzando o no la concentración de sentido, consciente de sí mismo o absorbido por la gravedad del "accidente". Orbita sentidos porque hay un cuerpo expuesto que, en principio, no simula y que, cuando la cámara se retire, es posible que siga allí donde esta lo encontró. Así, la cinematografía que pretenda tratar con el "acontecimiento", deberá asumir una especificidad de riesgo estético en tanto objeto crítico con la representación dominante: una cinematografía que cubra el sentido del envite del artista cuestionará el fondo de sus propias formas, su pensamiento, su ética, su fracaso... su autoría deberá "exponerse". Veamos unos ejemplos de documentales que se apropian la "exposición" presentando una ficción como verdad; en el déficit de conciencia del todo lo que es, es visible, anida un consenso que afirma esto es una pipa.

Le Mystère Picasso (Clouzot, 1956). Filmada en Cannes, en casa del pintor. Clouzot, quien tardó meses en convencer a Picasso, provenía técnica y conceptualmente del cine de ficción comercial, quizá por eso no pondera la dificultad de producir en contacto con lo llamado real, y empuja a Picasso a una especie de gymkhana: atendiendo a la excelencia de un hacer desgajado de Picasso, le obliga a parar, a arrancar, a cambiar sus horarios de trabajo, a hacerlo delante de gente... Construye un "accidente" espectacular (Nancy, 2001, p. 174): por la "apropiación", pensamiento y vida psíquica de Picasso se absorben y omiten; se filman cristales pintándose y telas atravesadas con una tinta especial que Picasso nunca usa, son improvisaciones. La explotación espectacular de la habilidad genial, relega al pintor a un estar laboral "sin abandono". Picasso, acabada la grabación, destruye las pinturas y dibujos producidos en los tres meses de rodaje. Premio 
del Jurado, en Cannes, en 1956. Clouzot aporta, escribe Bazin, que la duración puede incorporarse a la obra (Bazin, 1956, p.26); y quizá haber proporcionado al poder hegemónico una estética cinematográfica del control.

Ein Bild von Sarah Schumann (Farocki, 1976). Estrenada en la televisión alemana WDR en 1978, en Kunstgeschichten (Historia del Arte), se rueda entre diciembre de 1975 y marzo de 1976, en el estudio de Sarah Schumann, en Charlottenburg, Berlín, y documenta el proceso de creación de un cuadro. Faroki, militante y cineasta resistente, ya entonces problematiza la representación muy por delante de Clouzot. Schumann, activista feminista (organiza la exposición Künstlerinnen International 1877-1977, en 1977, primera sólo para mujeres). Farocki, voz en off, amigo y compañero de Schumann en el activismo político en el Berlín de los sesenta, la presenta inclinada sobre su obra colocada sobre una mesa. Primeros planos de las manos, del pincel, del crecimiento del cuadro, Sarah siempre mediada por el trabajo. Hasta el minuto veintidos no la presenta completa, en pie junto al cuadro acabado, mirando a cámara. No domina el espectáculo, como en Clouzot, pero subsiste la conciencia ingenua: el compromiso político traza la estética de la mujer trabajando; pero la presentación acrítica de Schumann pintando impone una ficción como verdad. Ficción emitida como verdad por la televisión alemana. La década de la "exposición" y de la "comunidad" es la siguiente.

El sol del membrillo (Erice, 1992). Es la que asume más elementos del cine de ficción comercial, sin reconocer su condición ficcional. Da a pensar que los coguionistas — cineasta-pintor-procuran compromisos mutuos repartidos entre la obsesión por la mímesis del pintor y el magistral recurso a la poesía del cineasta. ¿Desde dónde se hace la poesía? En el régimen escópico que Martin Jay denomina "barroco", característico de la modernidad (Jay, 1987), dentro del cual podría situarse la reconocida estética de Erice, la autoría del documento visual mira la diferencia expresando la sensación que le produce la percepción del objeto ignoto desde su condición de individuo: mediado por lo sublime, lo onírico, lo extraño, lo sensual en la autoría, la singularidad a presentar se construye desde una autoría que habla de sí misma. Erice escribe, filma y monta un inconsciente de Antonio López para entremezclarlo con el "accidente", sustituye lo ignoto por una convención social (Barthes, 1980, p.10). Premio del Jurado en el Festival de Cannes, 1992.

\subsection{Dispositivo cinematográfico. No puedes presentar contra lo que sabes.}

El paso humano dado en la ceguera del Principio de Incertidumbre (Hawking, 1988), problematiza producir (tomar) un documento (medida) en contacto con el "acontecimiento" (partícula); y lo que funciona como grado en la producción del artista, es lo que la separa de cualquier otra forma de producción. La primera acepción etimológica del latín gradus "grado", es "paso". Otro significado de esta palabra hace referencia a una ordenación, de menor a mayor, o al revés, por ejemplo. Ambos significados operan como función en la "exposición”. La producción artística crítica, en tanto "sitúa la separación en el tejido consensual de lo real" (Rancière, 2010, p.78), supone una investigación que implementa la incertidumbre de una forma experimental acientífica y compartida — a veces gesto a gesto compartido— porque tal como declara Nancy en Wunderblock, el oficio del artista, como el del filósofo, es tratar de desvelar aquello que permanece oculto; pero introduciéndose en ello, por eso acientífica. El "paso" del artista dentro de la segunda acepción afectaría una supuesta escala social de productores construida sobre la presencia reiterada en el tiempo de producción de la forma del ser de $s u$ existencia: el sentido "en-común" que supone producir la obra, lo cual no subraya una graduación cualitativa de la "exposición" sino una permanencia inevitable en ella mientras se crea, un gasto de la voluntad de producir mediado por el sentido de ser-con sin comparación posible. La primera acepción se sustancia a través del lazarillo de la intuición, pero ambas operan con conciencia de control del phatos, de la ruptura estética y, por ella, de la imposibilidad de adelantar efectos. Dar pasos una y otra vez en la oscuridad, abandonar durante una investigación una y otra vez el espacio de confort que supone construir desde las representaciones dominantes para intentar desocultar el ser que estas ocultan, conlleva encajar en el tiempo de producción la certeza de estar en permanente estado de "exposición". ¿Cómo incluir en la presentación del otro — atravesando el «accidente» de la fisicidad de su cuerpo en marcha, su "límite"— ese interior que, en el productor, coadyuva a producir a partir de su profunda oscuridad y que, tras sus gestos, descubrimos la estela de un fracaso? No se puede. Con todo, había que intentarlo, comprender qué era lo esencial en el "acontecimiento", y lo esencial era la llegada del espacio-tiempo que se sustanciaba en el ponerse a trabajar del cuerpo de Andrea Garay acarreando consigo esa profunda oscuridad que hace su singularidad y su incertidumbre a la vez que la nuestra, partición de oscuridad sin acceso y sin la cual no hay obra. Enriquecí esta idea con la proyectiva figura lacaniana del fantasma. Decido entonces trabajar sólo con el cuerpo productor... ¿con qué parte?; o tal vez con ¿todo?; y ¿cómo? Descartado el todo corporal por 
acercar peligrosamente la identidad al "accidente", elijo atender la sustentación del organismo: los pies. Existe un camino que recorrer del cual surge la verdad (Nancy, 2013, p.281), eso es todo. Pero se precisa algo más que los pies: en los pocos metros cuadrados donde se iban a producir los diecinueve cuadros, Andrea recorrería un impredecible itinerario ante nosotros, marcado por su inconsciente: le propuse grabar desde medio muslo hasta los pies, ella pintaría descalza con las piernas desnudas. Los lienzos quedarían fuera de campo en largos planos secuencia, mientras la sustentación de su cuerpo, además de mostrarnos el camino, nos recordaría una constante humana: la imposibilidad de presentar o representar la "exposición" del otro. Pensamos que, en esa instancia, la pintura también se producía como desbordamiento que inundaba el fondo desde el que surgían estas mismas formas críticas, permitiendo circunnavegar el "accidente" y tratar con el sentido del "acontecimiento", constituyendo un "fondo subversivo" (Deleuze, 1989, p.176). Se incorpora al fondo una puesta en valor de la oscuridad que acompaña la existencia humana, "el fondo de las formas está hecho del susurro de su tejerse" (Nancy, 2006, p.17). Pensamos en el camino, en los gestos de los dedos de los pies, en el hecho de caminar descalza en verano y en invierno... Establecida la pared donde sujetar cada cuadro, se coloca paralelamente a ésta la cámara, a unos $80 \mathrm{~cm}$ de la pared: el eje longitudinal del objetivo atravesando perpendicularmente el camino que Andrea recorrería mil veces para acceder al cuadro todos los cuadros. Con la cámara elevada $15 \mathrm{~cm}$ sobre el suelo, el lienzo queda fuera de campo por el lado izquierdo del encuadre. Se graban la primera y la última hora de ejecución de cada cuadro, un proceso de 38 horas. Cada hora grabada compuesta por tres planos secuencia consecutivos de 20 minutos, obligados por el tipo de cámara. El montaje, sin causalidad narrativa, se estructura en diecinueve paneles inspirados en la tradición del archivo (Wunderblock piensa el archivo desde Freud en su Notiz über den Wunderblock, 1925), presentando, junto a otros materiales proyectuales, las diecinueve ejecuciones en planos de duración variable a partir de la gestualidad portadora de sentido indeterminado manifestado en pies y piernas por el inconsciente de Andrea Garay.

\section{Referencias}

BARTHES, R. (1980) S/Z. Madrid: Siglo XXI Editores.

BAUDRILLARD, J. (2006). La agonía del poder. Madrid: Círculo de Bellas Artes.

BAZIN, A. (1956). "Un film bergsonien : Le Mystère Picasso" en Cahiers du Cinéma, 60, p.25-28.

BURGIN, v. (2004). "Ver el sentido" en Ribalta, J. Efecto real. Barcelona: Editorial Gustavo Gili.

DELEUZE, G. (1989). Lógica del sentido. Barcelona: Paidós.

DERRIDA, J. (2002). “El cine y sus fantasmas” en Desobra. Vol. 1 p. 93-106. <http://digibug.ugr.es/handle/10481/34315> [Consulta: 15 de julio de 2016]

HAWKING, S.W. (1988). "Principio de incertidumbre" en Hawking, S.W. Historia del tiempo. Barcelona: Editorial Crítica.

Ein Bild von Sarah Schumann (Dir. Harun Farocki). Harun Farocki Filmproduktion. 1978.

El sol del membrillo (Dir. Victor Erice). Igeldo P.C / M. Moreno P.C / Instituto de Cinematografía y Artes Audiovisuales. 1992.

JAY, M. (2003). "Regímenes escópicos de la modernidad” en Jay, M. Campos de fuerza. Buenos Aires: Editorial Paidós.

Le Mystère Picasso (Dir. H.G. Clouzot). Filmsonor. 1956.

LEGAZ, A., GARAY, A.(2019). 20 espejos suceden. < https://alfonsolegaz.tumblr.com/20.MIRRORS.HAPPEN> [Consulta:1 de junio de 2019].

MASSó, J. (2015). Figuras de "lo común" en el pensamiento estético de Jean-Luc Nancy. Tesis doctoral. Madrid: Universidad Complutense de Madrid. < https://eprints.ucm.es/34231/> [Consulta: 14 de junio de 2019].

NANCY, J.-L (2001). La comunidad desobrada. Madrid: Arena Libros.

NANCY, J.-L (2006). “La imagen: Mímesis \& Méthexis” en Escritura e Imagen, Vol. 2, 7-22. 〈http://digibug.ugr.es/handle/10481/34315>

[Consulta: 26 de marzo de 2015].

NANCY, J-L. (2013). La partición de las artes. Valencia: Pre-Textos.

RANCIÈRE, J. (2010). "Las paradojas del arte político", en Rancière, J. El espectador emancipado. Buenos Aires: Ediciones Manantial. 